\title{
COMPARISON OF HEMODYNAMIC STABILITY WITH CISATRACURIUM AND ATRACURIUM IN PATIENTS WITH LOW EJECTION FRACTION UNDERGOING CORONARY ARTERY BYPASS GRAFTING
}

\author{
Mehwish Naseer, Imran Bashir, Vaqar Ilahi Paracha, Kaleem Ahmad, Imtiaz Ahmed Chaudhry, Tahseen Ahmed \\ Army Cardiac Centre, Lahore/National University of Medical Sciences (NUMS) Pakistan
}

\begin{abstract}
Objective: To compare the hemodynamic stability with cisatracurium and atracurium in patients with low ejection fraction undergoing coronary artery bypass grafting.

Study Design: Randomized controlled trial.

Place and Duration of Study: Department of Anesthesiology, Army Cardiac Center, Lahore, from Jan 2018 to Nov 2018.

Methodology: A total of 80 adult patients were recruited or invited to participate in this study. Further the cohort was divided in to two groups with respect to their treatment by draw method. Group I contained a total of 40 patients, which were given Cisatracurium $0.2 \mathrm{mg} / \mathrm{kg}$ at induction of anesthesia. The group II patients constitute the same number but the treatment medication given was $0.5 \mathrm{mg} / \mathrm{kg}$ Atracurium at induction.

Results: Before anesthesia induction, pulse rate was $84.10 \pm 5.54 \mathrm{bpm}$ and $83.01 \pm 5.72 \mathrm{bpm}$ in group A and B, respectively $(p=0.385)$. At 4 minutes after anesthesia induction, pulse rate was $83.05 \pm 5.58 \mathrm{bpm}$ and $86.37 \pm 6.62$ bpm in group A and B, respectively $(p=0.017)$. Before anesthesia induction, mean arterial pressure was $71.07 \pm$ $7.62 \mathrm{mmHg}$ and $69.22 \pm 10.77 \mathrm{mmHg}$ in group $\mathrm{A}$ and $\mathrm{B}$, respectively $(p=0.378)$. At 4 minutes after anesthesia induction, mean arterial pressure was $68.22 \pm 8.17 \mathrm{mmHg}$ and $72.20 \pm 8.09 \mathrm{mmHg}$ in group A and $\mathrm{B}$, respectively $(p=0.032)$ table-II.

Conclusion: We may conclude from our study that although there is significant difference of the change in arterial blood pressure due to the both drugs. The group A was having more stable hemodynamic indexes where the drug administrated was Cisatracurium.
\end{abstract}

Keywords: Atracurium, Cisatracurium, Coronary artery bypass grafting, Ejection fraction, Hemodynamic.

This is an Open Access article distributed under the terms of the Creative Commons Attribution License (http://creativecommons.org/licenses/by/4.0), which permits unrestricted use, distribution, and reproduction in any medium, provided the original work is properly cited.

\section{INTRODUCTION}

During induction of anesthesia many depolarizing and non depolarizing agents are used in order to ease the tracheal intubation and also to ascertain optimum muscular relaxation when patients are undergoing surgery. With the aim to create a muscle relaxant which had no renal or hepatic effects, atracurium was developed as it is a non depolarizing agent with minimal adverse effects and intermediate duration of action. Even though atracurium is an ideal drug with intermediate duration of action it also has limited histamine releasing characteristics, therefore, large and rapid boluses of atracurium cannot be administered 1 .

Use of muscle relaxants is widely common

Correspondence: Dr Mehwish Naseer, Asst Prof of Anaesthesia, Army Cardiac Centre, Lahore Pakistan in many surgeries including general surgery for induction as well as maintenance of muscle relaxation 2,3 . The first and foremost use of muscle relaxants was done in 1942 and afterwards it was made necessary for all the surgical procedure undergoing in general anesthesia ${ }^{3,4}$. Muscle relaxants results in hemodynamic changes via the mechanism of releasing of histamine and ganglion blocks which in turn results in antimuscarine effects. Atracurium is a popular muscle relaxant all over the world. However atracurium does have a drawback as it also results in histamine release and results in hemodynamic changes which are not desired in patients with diseases of cardiovascular system ${ }^{5,6}$.

Cisatracurium is an isomer of atracurium. Its edge over atracurium is that it causes very low amount of histamine release and therefore results 
in minimal hemodynamic changes ${ }^{7-9}$. The release of histamine by muscle relaxants can cause severe tachycardia, hypotension and erythema of face and head. The greater the dose of the given drug the greater is the adverse effects. Severity of these side effects also depends on the speed of action of certain drug 9 .10.

Study of the literature shows that, very few studies have been done regarding the comparison of atracurium and cisatracurium in terms of their hemodynamic effects, especially in patients with low ejection fraction and undergoing coronary bypass graft surgery. No local study could be found regarding hemodynamic comparison of atracurium and cisatracurium in coronary artery bypass graft surgery of patients with low ejection fraction. Therefore we are performing this study so that better recommendations can be made regarding muscle relaxant to be used in such patients undergoing general anesthesia.

\section{METHODOLOGY}

It is a randomized control trial which was conducted in department of Anesthesia, Army Cardiac Center, Combined Military Hospital, Lahore, from January 2018 to November 2018. Ethical approval for this study was taken from the ethics board of the institute. Sample size was calculated using the reference study ${ }^{10}$. Non probability consecutive type of sampling technique was used to collect the sample. A total number of 80 patients were included in this study after taking informed consent from each patients or their guardian. Lottery method was used to divide the patients into two equal groups, i.e. group A and group B. Group A consisted of 40 patients in which cisatracurium at the dose of $0.2 \mathrm{mg} / \mathrm{kg}$ was used at the time of induction of anesthesia. Similarly in group B 40 patients were administered with atracurium at the dose of $0.5 \mathrm{mg} / \mathrm{kg}$ at the time of induction of general anesthesia. Other than that similar protocol was given to all patients for induction of general anesthesia i.e. morphine at dose of $0.2 \mathrm{mg} / \mathrm{kg}$ and propofol at dose of $2 \mathrm{mg} / \mathrm{kg}$. Maintenance of anesthesia was done with isoflurane at the dose of $1.2 \%$.
Exclusion of patients was done on the following criteria; patients with heart blocks, patients with normal ejection fraction, patients with arrhythmias, patients with intra aortic balloon pump, patients undergoing emergency surgeries and patients undergoing surgeries without the use of cardiopulmonary bypass. All patients aged 40 to 60 belonging to either gender and having LV ejection fraction of $35 \%$ or lower were included in this study. A designed performa was used to record all the demographic as well as hemodynamic changes of the patients after the administration of the drugs. All the data was measured and recorded by the researcher himself. Heart rate, mean arterial blood pressure etc were noted before the induction of general anesthesia and also at 2 nd minute and 4 th minute after the induction or administration of the muscle relaxant (cisatracurium/atracurium).

\section{RESULTS}

Mean age and weight were $50.77 \pm 4.37$ years and $60.01 \pm 6.68 \mathrm{~kg}$ in group-A while $50.37 \pm 5.34$ years and $62.40 \pm 7.85 \mathrm{~kg}$ in group-B ( $p$-value= 0.715 and 0.145$)$, respectively. History of beta blocker use was $37.5 \%$ and $32.5 \%$ in group $\mathrm{A}$ and $\mathrm{B}$, respectively $(p=0.639)$. History of smoking and diabetes mellitus were present $40 \%$ and $35 \%$ of group-A patients while in $47.5 \%$ and $40 \%$ of group-B patients ( $p=0.499$ and 0.644$)$, respectively (table-I).

Before anesthesia induction, pulse rate was $84.10 \pm 5.54 \mathrm{bpm}$ and $83.01 \pm 5.72 \mathrm{bpm}$ in group A and $\mathrm{B}$, respectively $(p=0.385)$. At 2 minutes after anesthesia induction, pulse rate was $83.25 \pm 5.95$ bpm and $85.72 \pm 5.26 \mathrm{bpm}$ in group A and B, respectively $(p=0.052)$. At 4 minutes after anesthesia induction, pulse rate was $83.05 \pm 5.58 \mathrm{bpm}$ and $86.37 \pm 6.62 \mathrm{bpm}$ in group $\mathrm{A}$ and $\mathrm{B}$, respectively $(p=0.017)$. Before anesthesia induction, mean arterial pressure was $71.07 \pm 7.62 \mathrm{mmHg}$ and $69.22 \pm$ $10.77 \mathrm{mmHg}$ in group $\mathrm{A}$ and $\mathrm{B}$, respectively $(p=$ 0.378). At 2 minutes after anesthesia induction, mean arterial pressure was $69.30 \pm 6.47 \mathrm{mmHg}$ and $66.53 \pm 7.55 \mathrm{mmHg}$ in group $\mathrm{A}$ and $\mathrm{B}$, respectively $(p=0.082)$. At 4 minutes after anesthesia 
induction, mean arterial pressure was $68.22 \pm 8.17$ $\mathrm{mmHg}$ and $72.20 \pm 8.09 \mathrm{mmHg}$ in group $\mathrm{A}$ and $\mathrm{B}$, respectively $(p=0.032)$ (table-II).
ED95 (effective dose at which $95 \%$ patients become unresponsive) which is almost $0.3 \mathrm{mg} / \mathrm{kg}$, it does not alter the arterial blood pressure and

Table-I: Demographic data.

\begin{tabular}{|c|c|c|c|}
\hline Variable & Group-A & Group-B & $p$-value \\
\hline Age (years) & $50.77 \pm 4.37$ & $50.37 \pm 5.34$ & 0.715 \\
\hline Weight $(\mathrm{kg})$ & $60.01 \pm 6.68$ & $62.40 \pm 7.85$ & 0.145 \\
\hline History of Beta blocker use & $15(37.5 \%)$ & $13(32.5 \%)$ & 0.639 \\
\hline Smoking history & $16(40.0 \%)$ & $19(47.5 \%)$ & 0.499 \\
\hline Diabetes Mellitus & $14(35.0 \%)$ & $16(40.0 \%)$ & 0.644 \\
\hline \multicolumn{4}{|c|}{$\begin{array}{l}\text { *Data is entered as mean } \pm \text { SD or number (Percentage) } \\
\text { Table-II: Hemodynamics data. }\end{array}$} \\
\hline Variable & Group-A & Group-B & $p$-value \\
\hline \multicolumn{4}{|l|}{ Pulse Rate, Bpm } \\
\hline Before anesthesia induction & $84.10 \pm 5.54$ & $83.01 \pm 5.72$ & 0.385 \\
\hline At 2 min after induction & $83.25 \pm 5.95$ & $85.72 \pm 5.26$ & 0.052 \\
\hline At 4 min after induction & $83.05 \pm 5.58$ & $86.37 \pm 6.62$ & 0.017 \\
\hline \multicolumn{4}{|c|}{ Mean Arterial Pressure, $\mathrm{mmHg}$} \\
\hline Before anesthesia induction & $71.07 \pm 7.62$ & $69.22 \pm 10.77$ & 0.378 \\
\hline At 2 min after induction & $69.30 \pm 6.47$ & $66.53 \pm 7.55$ & 0.082 \\
\hline At 4 min after induction & $68.22 \pm 8.17$ & $72.20 \pm 8.09$ & 0.032 \\
\hline
\end{tabular}

\section{DISCUSSION}

Comparison of hemodynamic stability after the use of cisatracurium and atracurium was done in this study in patients with low ejection fraction undergoing coronary artery bypass grafting. Use of muscle relaxant is well established according to previous literature for the induction of general anesthesia by providing optimum muscle relaxation to facilitate the intubation process in patients undergoing coronary artery bypass grafting ${ }^{10-15}$.

Use of narcotic drugs in induction of general anesthesia causes bradycardia. Pancuronium is the oldest drug which was used to counter the bradycardia produced by these narcotic drugs at induction. Pancuronium is no longer used as a drug of choice for muscle relaxation because it has a long duration of action and causes tachycardia and therefore is not favorable in cases where early extubation is needed ${ }^{16}$.

Studies have shown that cisatracurium when used in patients undergoing coronary artery bypass graft surgery at the dose of six times the heart rate ${ }^{16,17}$.

Current study also supports the fact that cisatracurium had minimal effect on hemodynamic stability of patients undergoing coronary artery bypass grafting. In a previous study it was found that cisatracurium use was not associated with any rise of serum histamine levels. That study also reported that no significant hemodynamic changes were noted with the use of cisatracurium in 150 patients ${ }^{18}$.

In a previous study by Seluck et al ${ }^{19}$ compared cisatracurium with atracurium in patients undergoing bypass graft surgery. The ejection fraction of these 100 patients was between $42-45 \%$ and beta blockers and calcium channel blockers were used as premedication before surgery. They reported effective hemodynamic changes after the use of premedication. In contrast to their findings the results of study showed no effect of premedication on hemodynamic stability during surgery whereas hemodynamic indices were more stable in group of patients in which cisatracurium was used at the time of induction. 


\section{CONCLUSION}

We may conclude from our study that although there is significant difference of the change in arterial blood pressure due to the both drugs. The group A was having more stable hemodynamic indexes where the drug administrated was Cisatracurium.

\section{CONFLICT OF INTEREST}

This study has no conflict of interest to be declared by any author.

\section{REFERENCES}

1. Basta SJ. Histamine releasing potencies of atracurium, dimethyl tubocurarine and tubocurarine. Br J Anaesth 1983; 55(Suppl-1): S105-06.

2. Wang KY, Wang HW, Xin LF, Wang YW, Xue YL. Evaluation of high-concentration sevoflurane for induction and nasotracheal intubation without muscle relaxantfor infants with different pulmonary blood flow undergoing surgery for congenital heart diseases. Chin Med J (Engl) 2011; 124(24): 4144-48.

3. Devi VK, Jain N, Valli KS. Importance of novel drug delivery systems in herbal medicines. Pharmacogn Rev 2010; 4(7): 27-31.

4. Darbinian TM, Suddason Ch. Comparative evaluation of the effectiveness of the fractional (bolus) and continuous methods of administering muscle relaxants during general anesthesia. Anesteziol Reanimatol 1985; 1(2): 15-19.

5. Brinkmann M, Günnicker M, Freund U, Schieffer M, Peters J. Histamine plasma concentration and cardiovascular effects of non-depolarizing muscle relaxants: comparison of atracurium, vecuronium, pancuronium and pipecuronium in coronary surgical patients at risk. Anasthesiol Intensivmed Notfallmed Schmerz Ther 1998; 33(6): 362-66.

6. Jenks SJ, Conway BR, Hor TJ, Williamson RM, McLachlan S, Robertson C, et al. Hepatic steatosis and non-alcoholic fatty liver disease are not associated with decline in renal function in people with Type 2 diabetes. Diabet Med 2014; 31(9): 1039-46.

7. Weindlmayr-Goettel M, Gilly H, Kress HG. Does ester hydrolysis change the in vitro degradation rate of cisatracurium and atracurium? Br J Anaesth 2002; 88(4): 555-62.
8. Welch RM, Brown A, Ravitch J, Dahl R. The in vitro degradation of cisatracurium, the $\mathrm{R}$, cis- $\mathrm{R}^{\prime}$-isomer of atracurium, in human and rat plasma. Clin Pharmacol Ther 1995; 58(2): 132-42.

9. Siler JN, Mager JG, Wyche MQ. Atracurium: hypotension, tachycardia and bronchospasm. Anesthesiol 1985; 62(5): 645-46.

10. Doenicke A, Lorenz W, Hoernecke R, Nebauer AE, Mayer M. Histamine release after injection of benzodiazepines and of etomidate. A problem associated with the solvent propylene glycol. Ann Fr Anesth Reanim 1993; 12(2): 166-68.

11. Ghorbanlo M, Mohaghegh MR, Yazdanian F, Mehrdad M, Totonchi Z. A comparison between hemodynamic effects of cisatracurium and atracurium in patients with low functions of left ventricle who are candidate for open heart surgery. Med Arch 2016; 70(4): 265-68.

12. Brissac BR, Phiraï S, Larifla L, Atallah A, Hedreville M, Hedreville $\mathrm{S}$, et al. Hypertension and cardiovascular risk associated with obstructive sleep apnea in adult in Guadeloupe (French West Indies). Ann Cardiol Angeiol (Paris) 2015; 64(3): 132-38.

13. Odutayo A, Rahimi K, Hsiao AJ, Emdin CA. Blood pressure targets and absolute cardiovascular risk. Hypertension 2015; 66(2): 280-85.

14. Bishko OI, Harasym NP, Sanahurs'kyĩ DI. Antioxidant defense system state in blood plasma and heart muscle of rats under the influence of histamine and sodium hypochlorite. Ukr Biokhim Zh 2014; 86(6): 56-65.

15. Onorati F, Rubino AS, Cristodoro L, Scalas C, Nucera S, Santini $\mathrm{F}$, et al. In vivo functional flowmetric behavior of the radial artery graft: Is the composite Y-graft configuration advantageous over conventional aorta-coronary bypass? J Thorac Cardiovasc Surg 2010; 140(2): 292-97.

16. Parmentier P, Dagnelie P. Dose-related tachycardia induced by pancuronium during balanced anaesthesia with and without droperidol. Br J Anaesth 1979; 51(2): 157-60.

17. Gandevia SC, Killian K, McKenzie DK, Crawford M, Allen GM, Gorman RB, Hales JP. Respiratory sensations, cardiovascular control, kinaesthesia and transcranial stimulation during paralysis in humans. J Physiol 1993; 470(1): 85-107.

18. Berg CM, Heier T, Wilhelmsen V, Florvaag E. Rocuronium and cisatracurium-positive skin tests in non-allergic volunteers: deter mination of drug concentration thresholds using a dilution titration technique. Acta Anaesthesiol Scand 2003; 47(5): 576-82.

19. Selcuk M, Celebioglu B, Celiker V, Basgul E, Aypar U. Infusion and bolus administration of cisatracurium - effects on histamine release. Middle East J Anaesthesiol 2005; 18(2): 407-19. 